August 2006

\title{
Preventive treatment of migraine
}

Stephen Silberstein

Thomas Jefferson University

Follow this and additional works at: https://jdc.jefferson.edu/neurologyfp

Part of the Neurology Commons

Let us know how access to this document benefits you

\section{Recommended Citation}

Silberstein, Stephen, "Preventive treatment of migraine" (2006). Department of Neurology

Faculty Papers. Paper 19.

https://jdc.jefferson.edu/neurologyfp/19

This Article is brought to you for free and open access by the Jefferson Digital Commons. The Jefferson Digital Commons is a service of Thomas Jefferson University's Center for Teaching and Learning (CTL). The Commons is a showcase for Jefferson books and journals, peer-reviewed scholarly publications, unique historical collections from the University archives, and teaching tools. The Jefferson Digital Commons allows researchers and interested readers anywhere in the world to learn about and keep up to date with Jefferson scholarship. This article has been accepted for inclusion in Department of Neurology Faculty Papers by an authorized administrator of the Jefferson Digital Commons. For more information, please contact: JeffersonDigitalCommons@jefferson.edu. 


\title{
Preventive treatment of migraine
}

\author{
Stephen D. Silberstein \\ Jefferson Headache Center, 111 South 11th Street, Suite 8130, Philadelphia, PA 19107, USA \\ Email: stephen.silberstein@jefferson.edu
}

\begin{abstract}
Migraine is a common episodic pain disorder, the treatment of which can be acute to stop an attack or preventive to reduce the frequency, duration or severity of attacks. Preventive treatment is used when attacks are frequent or disabling. Many different medication groups are used for preventive treatment, including $\beta$-blockers, antidepressants and antiepileptic drugs. Their mechanisms of action include raising the threshold to migraine activation, enhancing antinociception, inhibiting cortical spreading depression, inhibiting peripheral and central sensitization, blocking neurogenic inflammation and modulating sympathetic, parasympathetic or 5-HT tone. In this article, I review evidence of the effectiveness of migraine preventive drugs. I also discuss the setting of treatment priorities.
\end{abstract}

\section{Introduction}

Migraine is a common episodic headache disorder that is characterized by attacks comprising various combinations of headache and neurological, gastrointestinal and autonomic symptoms. It has a one-year prevalence of $\sim 18 \%$ in women, $6 \%$ in men and $4 \%$ in children [1]. The International Headache Society (http://www.i-h-s.org/ ) subclassifies migraine into migraine without aura (1.1) and migraine with aura (1.2), the aura being the complex of focal neurological symptoms that most often precedes or accompanies an attack [2]. The pharmacological treatment of migraine can be acute (abortive) or preventive, and patients with frequent severe headaches often require both approaches. Preventive migraine treatment also includes nonpharmacological therapy, which is not discussed in this review. Preventive treatment is used to reduce the frequency, duration or severity of attacks. Additional benefits include improvement of responsiveness to acute attack treatment, improvement of function and reduction in disability. Preventive treatment might preclude the progression of episodic migraine to chronic migraine and result in reductions in the cost of health care [3]. In this article, I present background information about migraine physiology, followed by a discussion of the available preventive medications. This is divided into older generic drugs, newer, recently studied medications and other drugs for which there is limited evidence of efficacy or that are perceived as natural products.

Guidelines for the preventive treatment of migraine have been developed in the USA [4]. Indications include:

i. attacks that significantly interfere with a patient's daily routine, despite appropriate acute treatment;

ii. failure of, contraindication to or troublesome adverse events (AEs) from acute

This is the author's final version prior to publication in Trends in Pharmacological Sciences 27(8):410-415, August 2006. The published version is available at http://dx.doi.org/10.1016/j.tips.2006.06.003, copyright $\odot 2006$ Elsevier Ltd. 
medications;

iii. acute medication overuse;

iv. very frequent headaches (more than two per week);

v. patient preference;

vi. special circumstances such as hemiplegic migraine or attacks with a risk of permanent neurological injury.

Prevention is not being used to the extent that it should be; only $5 \%$ of all migraineurs currently use preventive therapy to control their attacks [5].

Many medication groups are used for preventive migraine treatment (Table 1). The choice of preventive medication is empiric; it is influenced by efficacy, AEs and the patient's coexistent and comorbid conditions [1]. The chosen preventive agent should be started at a low dose and increased slowly until therapeutic effects develop or the ceiling dose is reached. A full therapeutic trial can take two to six months.

\section{Table 1. Preventive medications}

\begin{tabular}{|c|c|}
\hline Drug & Potential mechanism \\
\hline ACE inhibitors and angiotensin receptor antagonists & $\begin{array}{l}\text { Enkephalinase inhibition? } \\
\text { Enhance antinociception }\end{array}$ \\
\hline \multicolumn{2}{|l|}{ Anticonvulsants } \\
\hline Topiramate $^{\mathrm{a}}$, valproate ${ }^{\mathrm{a}}$, gabapentin, lamotrigine & $\begin{array}{l}\text { Inhibit CSD, block NI, inhibit CS } \\
\text { Enhance antinociception }\end{array}$ \\
\hline \multicolumn{2}{|l|}{ Antidepressants } \\
\hline $\begin{array}{l}\text { TCAs, SNRIs, SSRIs } \\
\text { }{ }^{\mathrm{b}} \text {-Adrenoceptor blockers }\end{array}$ & Inhibit CSD, enhance antinociception \\
\hline Propranolol , timolol ${ }^{\mathrm{a}}$, nadolol, atenolol & Inhibit CSD, decrease sympathetic activity \\
\hline \multicolumn{2}{|l|}{ Calcium channel antagonists } \\
\hline Flunarizine & Inhibits CSD, blocks dopamine receptor, inhibits NI \\
\hline Verapamil & Inhibits CSD \\
\hline \multicolumn{2}{|l|}{ Neurotoxins } \\
\hline $\begin{array}{l}\text { Botulinum toxin } \\
\text { 5-HT antagonists }\end{array}$ & Inhibit CS \\
\hline Methysergide, methergine & Inhibit CSD, inhibit NI \\
\hline Others & \\
\hline NSAIDS & Block prostaglandin synthesis, inhibit CS \\
\hline Riboflavin, CoQ10, magnesium ${ }^{\mathrm{b}}$ & Normalize energy metabolism \\
\hline Feverfew , butterroot & Inhibit CS? \\
\hline
\end{tabular}

This is the author's final version prior to publication in Trends in Pharmacological Sciences 27(8):410-415, August 2006. The published version is available at http://dx.doi.org/10.1016/j.tips.2006.06.003, copyright (C) 2006 Elsevier Ltd. 


\section{Mechanism of action of preventive medications}

The migraine aura is probably due to spreading depression (SD), a wave of electrical activity (excitation followed by depression) that moves across the cerebral cortex at a rate of 2-3 $\mathrm{mm} / \mathrm{min}$. It is characterized by shifts in cortical steady-state potential, transient increases in $\mathrm{K}^{+}$, nitric oxide and glutamate, and transient increases followed by sustained decreases in cerebral blood flow [6,7] (Figure 1).

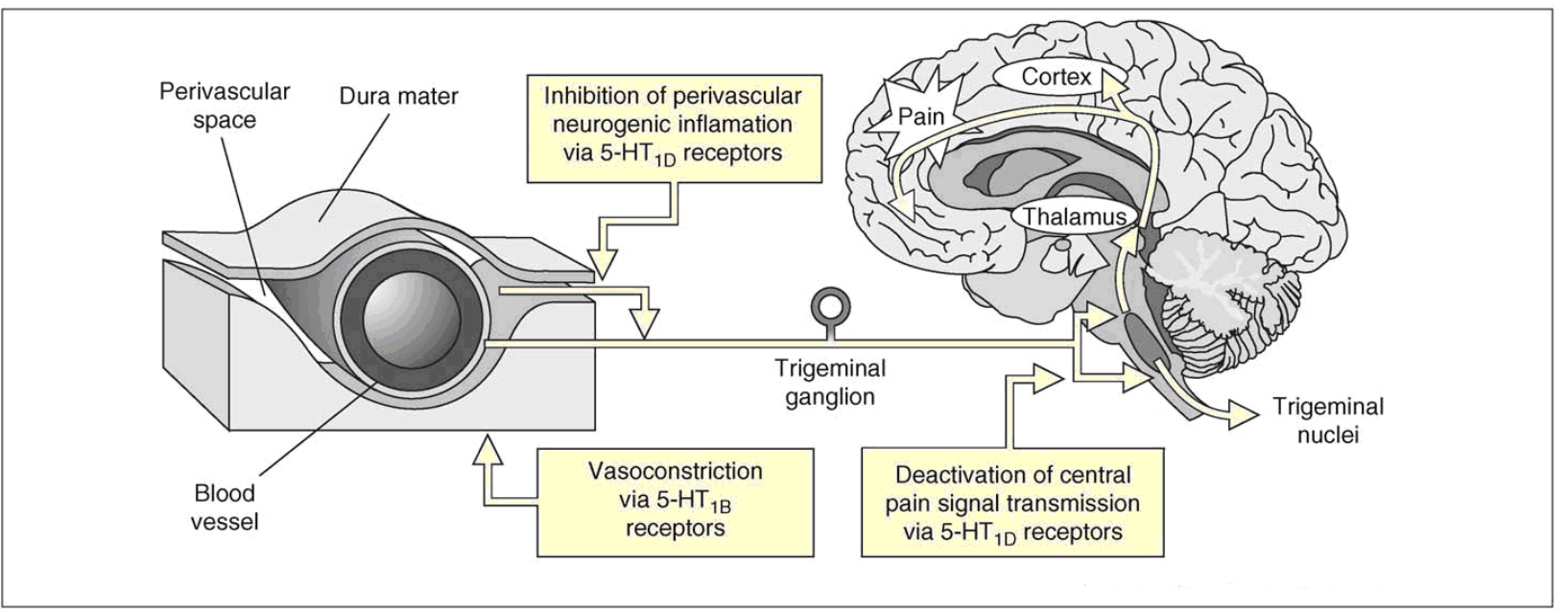

Figure 1. Migraine mechanisms. The migraine aura is due to CSD in a more sensitive CNS. The headache is due to activation of trigeminal dural and perivascular afferents, resulting in neurogenic-mediated inflammation and plasma protein extravasation. Headache is maintained by the sensitization of TNC neurons. SD can lead to the activation of trigeminal neurons and results in the release of nitric oxide, glutamate and protons that can activate trigeminal afferent nerves. Headache in the absence of aura might be generated by SD in the cerebellum or silent areas of the cortex. In addition, parasympathetic nerves that are under brainstem control might activate trigeminal neurons. The TNC is subject to both inhibitory and facilitatory descending modulation. Preventive drugs can inhibit CSD by reducing central excitability, perhaps in part by blocking gap junctions. Preventive drugs can also enhance descending inhibitory modulation and inhibit neurogenic inflammation or central pain transmission. In addition, they might work on earlier, still unknown, parts of the migraine cascade.

Headache probably results from the activation of meningeal and blood vessel nociceptors, combined with a change in central pain modulation. Headache and its associated neurovascular changes are subserved by the trigeminal system. Trigeminal sensory neurons contain substance $\mathrm{P}$ (SP), calcitonin-gene-related peptide and neurokinin A. In animal models, stimulation results in the release of SP and calcitonin-gene-related peptide from sensory C-fiber terminals, and neurogenic inflammation (NI) [7]. However, the role of SP in the pathophysiology of human migraine is unclear [8].

In animal experiments, neuropeptides interact with the blood vessel wall, producing dilatation, plasma protein extravasation and platelet activation [9]. Neurogenic inflammation sensitizes

This is the author's final version prior to publication in Trends in Pharmacological Sciences 27(8):410-415, August 2006. The published version is available at http://dx.doi.org/10.1016/j.tips.2006.06.003, copyright (C) 2006 Elsevier Ltd. 
nerve fibers (peripheral sensitization), which then respond to previously innocuous stimuli such as blood vessel pulsations, causing, in part, the pain of migraine. Central sensitization of trigeminal nucleus caudalis (TNC) neurons can also occur and might have a key role in maintaining the headache [10]. Brainstem activation also occurs in migraine without aura, in part because of increased endogenous antinociceptive system activity. The migraine aura can trigger headache; SD activates trigeminovascular afferents. What initiates the activation of trigeminovascular afferents in the absence of a clinical aura? Potential mechanisms include SD in silent areas of the cerebral cortex or cerebellum. In addition, trigeminal afferents might be activated by events initiated in the brainstem. Stress can also activate meningeal plasma cells via a parasympathetic mechanism, leading to nociceptor activation [11].

Most migraine preventive drugs were designed to treat other disorders. 5-HT antagonists were developed based on the concept that migraine is due to excess 5-HT. Antidepressants downregulate 5-HT2 and b-adrenoceptors. Anticonvulsant medications decrease glutamate levels and enhance GABA. The potential mechanisms of migraine preventive medications include:

i. raising the threshold to migraine activation by stabilizing a more reactive nervous system;

ii. enhancing antinociception;

iii. inhibiting SD;

iv. inhibiting peripheral and/or central sensitization;

v. blocking neurogenic inflammation;

vi. modulating sympathetic, parasympathetic or 5-HT tone.

Oshinski and Luo found that descending control from the upper brainstem, through 5-HTmediated and norepinephrine-mediated systems, modulates the TNC and prevents central sensitization [12]. Ayata et al. have recently shown that preventive medications given chronically, but not acutely, block SD [13].

New targets are being evaluated. Gap junctions are intercellular channels that enable the diffusion of small molecules (up to $1 \mathrm{kDa}$ ). Vertebrate gap junction channels comprise 12 protein subunits called connexins. Gap junctions have a central role in mechanisms underlying the initiation and propagation of SD. Gap junction inhibitors abolish both astrocytic $\mathrm{Ca}^{2+}$ waves in culture and SD [14].

The gap junction inhibitor tonabersat $\{(-)$-cis-6-acetyl-4S-3-chloro-4-fluoro-benzoylamino-3,4dihydro-2,2-dimethyl-2H-benzo[ $p]$ pyran-3S-ol $\}$ has entered clinical trials for migraine. Tonabersat inhibits cortical spreading depression (CSD), CSD-induced nitrous oxide release and cerebral vasodilatation. It does not constrict isolated human blood vessels but it does inhibit trigeminally induced craniovascular effects [15].

\section{Older migraine preventive agents}

\section{$\beta$-Blockers}

The mechanism of action of $\beta$-blockers is not clear but it could occur by the inhibition of $\beta_{1^{-}}$ mediated mechanisms [16]. $\beta$-Blockers, the most widely used class of prophylactic migraine drug, are $\sim 50 \%$ effective at producing a $>50 \%$ reduction in attack frequency and include

This is the author's final version prior to publication in Trends in Pharmacological Sciences 27(8):410-415, August 2006. The published version is available at http://dx.doi.org/10.1016/j.tips.2006.06.003, copyright $\odot 2006$ Elsevier Ltd. 
propranolol, nadolol, atenolol, metoprolol and timolol [17]. The relative efficacy of $\beta$-blockers has not been established; choice is based on $\beta$-selectivity, convenience, AEs and patient reactions. $\beta$-Blockers with intrinsic sympathomimetic activity (e.g., acebutolol, alprenolol, oxprenolol and pindolol) are not effective for migraine prevention. $\beta$-Blockers can produce behavioral AEs such as drowsiness, fatigue, lethargy, sleep disorders, nightmares, depression, memory disturbance and hallucinations, and should be avoided when patients are depressed. Decreased exercise tolerance limits their use by athletes. Less common AEs include impotence, orthostatic hypotension and bradycardia [18].

\section{Antidepressants}

There are several different classes of antidepressant that have different mechanisms of action. In animal pain models, antidepressants potentiate the effects of co-administered opioids [16]. Amitriptyline (a tricyclic antidepressant) is the only antidepressant with consistent support for efficacy [17]. AEs include increased appetite, weight gain, dry mouth and sedation; cardiac toxicity and orthostatic hypotension occasionally occur. Selective 5-HT reuptake inhibitors (SSRIs) are probably not effective at preventing migraine, whereas the results of open and smaller studies indicate that selective norepinephrinereuptake inhibitors (SNRIs) are effective [19]. The mechanism by which antidepressants prevent headache is unclear but it does not result from treating masked depression.

\section{$\mathrm{Ca}^{2+}$ channel antagonists}

$\mathrm{Ca}^{2+}$ channel antagonists were introduced for the treatment of migraine on the assumption that they prevent hypoxia of cerebral neurons, contraction of vascular smooth muscle and inhibition of the $\mathrm{Ca}^{2+}$-dependent enzymes involved in prostaglandin formation. Perhaps it is their ability to block 5-HT release, interfere with neurovascular inflammation or interfere with the initiation and propagation of SD that is crucial [16]. The discovery that an abnormality in an a1A subunit (P/Q channel) can produce familial hemiplegic migraine has led to a search for more-fundamental associations [20].

Of the drugs in this class [17], flunarizine is effective at preventing migraine, whereas nimodipine and nifedipine are probably not. The efficacy of verapamil, despite its wide use in the USA (because flunarizine is unavailable), is uncertain, and its most common AE is constipation. The AEs of flunarizine include parkinsonism, depression and weight gain. These are typical of dopamine antagonists and indicate an alternative mechanism of action.

\section{Newer drugs}

\section{Anticonvulsants}

Because of the proven effectiveness of anticonvulsants and because of the belief that migraine is due to CNS hyperexcitability, headache experts increasingly recommend anticonvulsant medication for migraine prevention. With the exception of topiramate, valproic acid and zonisamide, anticonvulsants can interfere substantially with the efficacy of oral contraceptives $[21,22]$. They are discussed in order of efficacy in terms of migraine prevention.

This is the author's final version prior to publication in Trends in Pharmacological Sciences 27(8):410-415, August 2006. The published version is available at http://dx.doi.org/10.1016/j.tips.2006.06.003, copyright $\odot 2006$ Elsevier Ltd. 


\section{Topiramate}

Topiramate was originally synthesized as part of a research project to develop structural analogs of fructose-1,6-diphosphate that could inhibit the enzyme fructose 1,6-bisphosphatase, thereby blocking gluconeogenesis, but it has no hypoglycemic activity. Topiramate was originally marketed for the treatment of epilepsy [23] but is now approved by the Food and Drug Administration (FDA, http://www.fda.gov/ ) for migraine treatment. Topiramate is rapidly and almost completely absorbed, not extensively metabolized [24] and it readily enters the CNS $[25,26]$. It is not associated with significant reductions in estrogen exposure at doses $<200$ $\mathrm{mg} /$ day.

Topiramate can influence the activity of some types of voltage-activated $\mathrm{Na}^{+}$and $\mathrm{Ca}^{2+}$ channels, GABAA receptors and the AMPA/kainate subtype of glutamate receptor [27,25]. It also inhibits some isozymes of carbonic anhydrase (CA) and exhibits selectivity for CA II and CA IV [28].

Topiramate blocks $\mathrm{Na}^{+}$channels in a voltage-sensitive, use-dependent manner [29]. It reduces the amplitude of tetrodotoxin-sensitive voltage-gated $\mathrm{Na}^{+}$currents in rat cerebellar granule cells, as measured by whole-cell current-clamp recordings [30]. Its effects on voltage-activated $\mathrm{Na}^{+}$and $\mathrm{Ca}^{2+}$ channels, GABAA receptors and AMPA/kainate receptors are regulated by protein phosphorylation [31-34]. Subunits of each complex are phosphorylated by protein kinase (PK)A, $\mathrm{PKC}$ and possibly $\mathrm{Ca} /$ calmodulin-activated kinases. Topiramate might prevent PKA from phosphorylating these moieties, which would shift a population of channels towards the dephosphorylated state, thereby modulating channel and receptor activity [26].

Neuron activation within the trigeminocervical complex is likely to be the biological substrate for pain in migraine and cluster headache. Topiramate reduces superior-sagittal-sinus-evoked firing of neurons in the trigeminocervical complex in a dose-dependent fashion [35]. This inhibition is a plausible mechanism of its action in migraine prevention. Topiramate was effective in several open-label and pilot studies and in three large, multicenter, randomized, double-blind, placebo-controlled clinical trials. In addition, its chronic use has been associated with weight loss rather than weight gain.

Two large, pivotal, multicenter, randomized, double-blind, placebo-controlled clinical trials assessed the efficacy and safety of topiramate (50, 100 and $200 \mathrm{mg} /$ day) in migraine prevention and found it to be effective at all doses [36,37]. A third trial compared two doses of topiramate (100 mg/day and $200 \mathrm{mg} /$ day) with placebo or propranolol (160 mg/day) [38]. A dose of 100 $\mathrm{mg} /$ day of topiramate was superior to placebo in terms of migraine prevention. The results of the topiramate $100-\mathrm{mg} /$ day and the propranolol groups were similar. The $100-\mathrm{mg} /$ day dose of topiramate has the best effectiveness: AE ratio.

The most common AEs of topiramate are paresthesia, fatigue, decreased appetite, nausea, diarrhea, weight decrease, taste perversion, hypoesthesia and abdominal pain. Common CNS AEs are somnolence, insomnia, memory difficulties, language problems, concentration difficulties, mood problems and anxiety. Renal calculi can occur: their reported incidence is $\sim 1.5 \%$, representing a twofold to fourfold increase compared with the estimated occurrence in the general population [39]. Acute myopia associated with secondary angle-closure glaucoma

This is the author's final version prior to publication in Trends in Pharmacological Sciences 27(8):410-415, August 2006. The published version is available at http://dx.doi.org/10.1016/j.tips.2006.06.003, copyright $\odot 2006$ Elsevier Ltd. 
has been reported infrequently in patients receiving topiramate [40]. Oligohidrosis has also been reported in association with an elevation in body temperature.

Weight loss seems to be greatest in patients who are heavier at the onset of treatment and is seen most commonly in women [41]. The exact mechanism underlying weight loss is unclear. Rats given topiramate showed decreased levels of body fat, in addition to acutely reduced food intake and an increased metabolic rate. These animals also had decreased levels of total insulin, leptin and corticosterone [42]. Topiramate inhibits fat deposition, and the activity of lipoprotein lipase is reduced in adipose tissue in topiramate-treated rats [43].

Valproic acid

Valproic acid is a simple eight-carbon, two-chain fatty acid with anticonvulsant activity in a wide range of experimental epilepsy models. The mechanism of action of valproate in migraine prevention might be related to the facilitation of GABA-mediated neurotransmission [44-48]. Valproate enhances GABA activity within the brain by inhibiting its degradation, stimulating its synthesis and release, and directly enhancing its postsynaptic effects. The valproate concentration required to inhibit GABA transaminase is greater than that which occurs during therapy. However, active metabolites (e.g. 2-en-valproic acid) accumulate in the brain, have an anticonvulsant effect and cause GABA accumulation in vivo [45]. Other potential mechanisms of action include direct effects on neuronal membranes (suppressing induced and spontaneous epileptiform activity), inhibition of kindling and reduction of excitatory neurotransmission by aspartate by blocking its release $[47,48]$. Valproate also attenuates NI by interacting with the GABAA receptor, which might be on the parasympathetic nerve fibers that project from the sphenopalatine ganglia; in so doing, it attenuates nociceptive neurotransmission [45]. Increased central enhancement of GABAA activity might enhance central antinociception [49]. Valproate also interacts with the central 5-HT system and reduces the firing rate of midbrain 5-HTcontaining neurons [49].

Consistent evidence supports the efficacy of divalproex sodium (approved by the FDA) [17], sodium valproate [17] and the extended-release formulation [50]. The effective dose for migraine of both divalproex sodium and sodium valproate is lower than that for epilepsy. The most frequent AEs are nausea, alopecia, tremor, asthenia, dyspepsia, somnolence and weight gain [51]. Hepatotoxicity and pancreatitis are the most serious AEs but irreversible hepatic dysfunction is extremely rare in adults [52]. Divalproex carries a high risk of congenital abnormality [46].

\section{Gabapentin}

Gabapentin is used to treat certain forms of epilepsy, neuropathic pain and migraine. It binds with high affinity to two of the four known $\alpha_{2} \delta$ subunits $\left(\alpha_{2} \delta-1\right.$ and $\left.\alpha_{2} \delta-2\right)$ of voltage-gated Ca ${ }^{2+}$ channels. This produces inhibition of high-voltage-activated $\mathrm{Ca}^{2+}$ currents, resulting in a reduction of synaptic transmission. This could be how gabapentin reduces fast glutamatemediated and glycine-mediated synaptic transmission [53,54]. Gabapentin might be effective in migraine but the trial results are not conclusive [55-57]. The most common AEs are dizziness and drowsiness [17].

This is the author's final version prior to publication in Trends in Pharmacological Sciences 27(8):410-415, August 2006. The published version is available at http://dx.doi.org/10.1016/j.tips.2006.06.003, copyright $\odot 2006$ Elsevier Ltd. 


\section{Lamotrigine}

Lamotrigine blocks voltage-sensitive $\mathrm{Na}^{+}$channels, leading to the inhibition of neuronal glutamate release. Glutamate is essential for the propagation of CSD, which many believe to be the basis of the migraine aura [58]. Lamotrigine has been studied as part of a combination therapy for headache prevention in one relatively large, prospective, open-label trial of 65 patients, most of whom had chronic migraine [59]. There were $17(48.6 \%)$ responders, at a mean dose of $55 \mathrm{mg} /$ day. Those who had migraine with aura had a better response rate [12/18 (67\%)], including four of eight whose headaches were chronic. Another open-label study assessed the impact of lamotrigine on aura itself and found that the drug significantly reduced both the frequency and duration of aura [59].

Lamotrigine was not effective in a double-blind, randomized, parallel-groups trial [60]. This trial was flawed because lamotrigine treatment was started at the full dose of $200 \mathrm{mg} /$ day but, following a high incidence of skin rashes, a slow dose-escalation was introduced. Whereas studies indicate that lamotrigine is effective at preventing migraine with aura [61], it is unclear whether it is effective in the absence of aura.

\section{Other drugs}

The neurotoxin botulinum toxin type A (BTN-A) inhibits the release of the neurotransmitter acetylcholine at the neuromuscular junction, thereby inhibiting striated muscle contractions. However, pain reduction often occurs before the decrease in muscle contractions, indicating an alternative mechanism of action. The antinociceptive effect of BTN-A might be due to the ability of the toxin to block substance P release, as demonstrated using an in vitro culture system. BTNA blocks the local release of glutamate and substance $\mathrm{P}$ in an in vivo model. Furthermore, the production of FOS, a product of the immediate early gene $c f o s$, expressed with neuronal stimuli was prevented upon peripheral exposure to the toxin. These findings indicate that BTN-A blocks peripheral sensitization and indirectly reduces central sensitization. The recent hypothesis that migraine involves both peripheral and central sensitization could help to explain how BTN-A inhibits migraine pain by acting on these two pathways. Oshinsky has shown that injecting BTNA into the forehead of rodents prevents the central sensitization of wide-dynamic-range neurons in the TNC induced by applying an 'inflammatory soup' to the dura [62].

Pericranial BTN-A is effective as a prophylactic treatment of chronic moderate-to-severe migraine [63]. In one trial $(0,25$, or $75 \mathrm{U}$ of BTN-A injected symmetrically into glabellar, frontalis and temporalis muscles), the 25-U BTN-A treatment group fared significantly better than did the placebo group, but the 75-U group did not. BTNA treatment was well tolerated but high-dose BTN-A produced significantly more treatment-related AEs than did placebo. Recent studies indicate that BTN-A is no more effective than placebo at preventing infrequent migraine but is effective at preventing very frequent migraine [64].

Single controlled studies have supported the effectiveness of angiotensin-converting enzyme (ACE) inhibitors, angiotensin receptor antagonists, riboflavin, coenzyme Q10 (CoQ10) and butterroot at preventing episodic migraine. The evidence of effectiveness is better for NSAIDS and conflicted for feverfew [65].

This is the author's final version prior to publication in Trends in Pharmacological Sciences 27(8):410-415, August 2006. The published version is available at http://dx.doi.org/10.1016/j.tips.2006.06.003, copyright $\odot 2006$ Elsevier Ltd. 


\section{Concluding remarks: setting treatment priorities}

The goals of migraine preventive treatment are to reduce the frequency, duration or severity of attacks, improve responsiveness to acute attack treatment, improve function and reduce disability. It might also prevent the progression of episodic migraine to chronic migraine and result in reductions in the cost of health care. The preventive medications with the bestdocumented efficacy are the $\beta$-blockers, amitriptyline, divalproex and topiramate. Choice of medication is made based on the proven efficacy of a drug, the physician's informed belief about medications not yet evaluated in controlled trials, the AEs of a drug, patient preferences and headache profile, and the presence or absence of coexisting disorders [66].

Coexistent diseases have important implications for treatment. In some instances, two or more conditions can be treated with a single drug. However, this might be the exception rather than the rule. In an effort to use a single medication to treat two conditions, one might select a second-or third-tier choice for either or both conditions, which might not provide adequate treatment for either. Managing two separate illnesses often requires different timelines for assessing drug efficacy. It can take four or six weeks before improvement in migraine attack frequency or severity is measurable. However, hypertension responds to the initiation of, or a change in, treatment within one to two weeks. If individuals have more than one disease, certain categories of treatment might be contraindicated. Although monotherapy is preferred, it is sometimes necessary to combine preventive medications. Patients might require treatment with a 'therapeutic independence' approach, wherein each condition is treated separately. This requires one to assess which medication is best suited for each illness independently, and might need multiple physicians or specialists working together to provide optimal treatment recommendations. Controlled trials are needed to determine the true advantage of this combination treatment in episodic and chronic migraine.

New drugs for the preventive treatment of migraine are being developed based in part on an increased understanding of migraine mechanisms. Despite the existence of guidelines for migraine prevention, most patients are not receiving appropriate treatment. With increased awareness and the continued development of new treatment, I believe that more patients will receive appropriate care.

\section{References}

1. Silberstein, S.D. et al. (2002) Headache in Clinical Practice (2nd edn), Taylor \& Francis

2. Headache Classification Subcommittee of the International Headache Society (2004) The international classification of headache disorders (2nd edn). Cephalalgia 24 (Suppl. 1), 1160

3. Silberstein, S.D. et al. (2003) Migraine preventive medication reduces resource utilization. Headache 43, 171-178

4. Ramadan, N.M. et al. (2000) Evidenced-based guidelines for migraine headache in the primary care setting: pharmacological management for prevention of migraine. Neurology (http://www.neurology.org )

5. Lipton, R.B. et al. (2002) Migraine in the United States: epidemiology and patterns of

This is the author's final version prior to publication in Trends in Pharmacological Sciences 27(8):410-415, August 2006. The published version is available at http://dx.doi.org/10.1016/j.tips.2006.06.003, copyright $\odot 2006$ Elsevier Ltd. 
health care use. Neurology 58, 885-894

6. Olesen, J. et al. (1990) Timing and topography of cerebral blood flow, aura and headache during migraine attacks. Ann. Neurol. 28, 791-798

7. Pietrobon, D. and Striessnic, J. (2003) Neurobiology of migraine. Nat. Rev. Neurosci. 4, 386-398

8. Goadsby, P.J. et al. (1990) Vasoactive peptide release in the extracerebral circulation of humans during migraine headache. Ann. Neurol. 28, 183-187

9. Dimitriadou, V. et al. (1992) Ultrastructural evidence for neurogenically mediated changes in blood vessels of the rat aura mater and tongue following antidromic trigeminal stimulation. Neuroscience 48, 187-203

10. Burstein, R. and Jakubowski, M. (2004) Analgesic triptan action in an animal model of intracranial pain: a race against the development of central sensitization. Ann. Neurol. 55, $27-36$

11. Kandere-Grzybowska, K. et al. (2003) Stress-induced dura vascular permeability does not develop in mast cell-deficient and neurokinin-1 receptor knockout mice. Brain Res. 980, 213-220

12. Oshinsky, M. and Luo, J. (2006) Neurochemistry of a rat migraine model. Headache (in press)

13. Ayata, C. et al. (2006) Suppression of cortical spreading depression in migraine prophylaxis. Ann. Neurol. 59, 652-661

14. Theis, M. et al. (2005) Emerging complexities in identity and function of glial connexins. Trends Neurosci. 28, 188-195

15. Goadsby, P.J. (2005) Can we develop neurally acting drugs for the treatment of migraine? Nat. Rev. Drug Discov. 4, 741-750

16. Silberstein, S.D. and Goadsby, P.J. (2002) Migraine: preventive treatment. Cephalalgia 22, 491-512

17. Gray, R.N. et al. (1999) Drug treatments for the prevention of migraine headache. Prepared for the Agency for Health Care Policy and Research, contract 290-94-2025. National Technical Information Service Accession no. 127953

18. Linde, K. and Rossnagel, K. (2004) Propranolol for migraine prophylaxis. Cochrane Database Syst. Rev. CD003226

19. Ozyalcin, S.N. et al. (2005) The efficacy and safety of venlafaxine in the prophylaxis of migraine. Headache 45, 144-152

20. Ophoff, R.A. et al. (1996) Familial hemiplegic migraine and episodic ataxia type-2 are caused by mutations in the $\mathrm{Ca}^{2+}$ channel gene CACNLA4. Cell 87, 543-552

21. Coulam, C.B. and Annagers, J.R. (1979) New anticonvulsants reduce the efficacy of oral contraception. Epilepsia 20, 519-525

22. Hansten, P.D. and Horn, J.R. (1985) Drug Interaction Newsletter 5, 7-10

23. Silberstein, S.D. (2005) Topiramate in migraine prevention. Headache 45, S57-S65

24. Easterling, D.E. et al. (1988) Plasma pharmacokinetics of topiramate, a new anticonvulsant, in humans. Epilepsia 29, 662

25. MacDonald, R.L. and McLean, M.J. (1986) Anticonvulsant drugs: mechanisms of action. In Advances in Neurology (Escueta, A.D. et al., eds), pp. 713-736, Raven Press

26. Shank, R.P. et al. (2000) An overview of the preclinical aspects of topiramate:

This is the author's final version prior to publication in Trends in Pharmacological Sciences 27(8):410-415, August 2006. The published version is available at http://dx.doi.org/10.1016/j.tips.2006.06.003, copyright $\odot 2006$ Elsevier Ltd. 
pharmacology, pharmacokinetics, and mechanism of action. Epilepsia 41, S3-S9

27. Rogawski, M.A. and Porter, R.J. (1990) Antiepileptic drugs: pharmacological mechanisms and clinical efficacy with consideration of promising development stage compounds. Pharmacol. Rev. 42, 223-286

28. Dodgson, S.J. et al. (2000) Topiramate as an inhibitor of carbonic anhydrase isoenzymes. Epilepsia 41, S35-S39

29. DeLorenzo, R.J. et al. (2000) Effects of topiramate on sustained repetitive firing and spontaneous recurrent seizure discharges in cultured hippocampal neurons. Epilepsia 41, S40-S44

30. Zona, C. et al. (1997) Topiramate attenuates voltage-gated sodium currents in rat cerebellar granule cells. Neurosci. Lett. 231, 123-126

31. Krebs, E.G. (1994) The growth of research on protein phosphorylation. Trends Biochem. Sci. 19, 439

32. Roche, K.W. et al. (1996) Characterization of multiple phosphorylation sites on the AMP receptor GluR1 subunit. Neuron 16, 1179-1188

33. Wang, J.H. and Kelly, P.T. (1995) Postsynaptic injection of $\mathrm{CA}^{2+} / \mathrm{CaM}$ induces synaptic potentiation requiring CaMKII and PKC activity. Neuron 15, 443-452

34. Sigel, E. (1995) Functional modulation of ligand-gated GABAA and NMDA receptor channels by phosphorylation. J. Recept. Signal Transduct. Res. 15, 325-332

35. Storer, R.J. and Goadsby, P.J. (2003) Topiramate inhibits trigeminovascular traffic in the cat: a possible locus of action in the prevention of migraine. Neurology 60, A238

36. Silberstein, S.D. et al. (2004) Topiramate in the prevention of migraine headache: a randomized, double-blind, placebo-controlled, multiple-dose study. Arch. Neurol. 61, 490-495

37. Brandes, J.L. et al. (2004) Topiramate for migraine prevention: a randomized controlled trial. JAMA 291, 965-973

38. Diener, H.C. et al. (2004) Topiramate in migraine prophylaxis - results from a placebocontrolled trial with propranolol as an active control. J. Neurol. 251, 943-950

39. Sachdeo, R.C. et al. (1997) Topiramate monotherapy for partial onset seizures. Epilepsia 38, 294-300

40. Thomson Healthcare (2005) Physicians' Desk Reference (59th edn), Thomson Healthcare

41. Greenwood, R.S. (2000) Adverse effects of antiepileptic drugs. Epilepsia 41, S42-S51

42. York, D.A. et al. (2000) Effect of topiramate on body weight and body composition of Osborne-Mendel rats fed a high-fat diet: alterations in hormones, neuropeptide, and uncoupling-protein mRNAs. Nutrition 16, 967-975

43. Richard, D. et al. (2000) Influence of topiramate in the regulation of energy balance. Nutrition 16, 961-966

44. Löscher,W.(2002)Valproicacid:mechanismsofaction.In Antiepileptic Drugs (5th edn) (Levy, R.H. et al., eds), pp. 767-779, Lippincott Williams \& Wilkins

45. McNamara, J.O. (2001) Drugs effective in the therapy of the epilepsies. In Goodman's and Gilman's the Pharmacological Basis of Therapeutics (10th edn) (Hardman, J.G. et al., eds), pp. 521-548, McGraw-Hill

46. Silberstein, S.D. (2002) Valproic acid: clinical efficacy and use in other neurological disorders. In Antiepileptic Drugs (5th edn) (Levy, R.H. et al., eds), pp. 818-827, Lippincott Williams \& Wilkins

This is the author's final version prior to publication in Trends in Pharmacological Sciences 27(8):410-415, August 2006. The published version is available at http://dx.doi.org/10.1016/j.tips.2006.06.003, copyright $\odot 2006$ Elsevier Ltd. 
47. Rimmer, E.M. and Richens, A. (1985) An update on sodium valproate. Pharmacotherapy 5, 171-184

48. Chapman, A. et al. (1982) Mechanisms of anticonvulsant action of valproate. Prog. Neurobiol. 19, 315-359

49. Moskowitz, M.A. (1992) Neurogenic versus vascular mechanisms of sumatriptan and ergot alkaloids in migraine. Trends Pharmacol. Sci. 13, 307-311

50. Freitag, F.G. et al. (2002) A randomized trial of divalproex sodium extended-release tablets in migraine prophylaxis. Neurology 58, 1652-1659

51. Silberstein, S.D. and Collins, S.D. (1999) Safety of divalproex sodium in migraine prophylaxis: an open-label, long-term study (for the long-term safety of depakote in headache prophylaxis study group). Headache 39, 633-643

52. Silberstein, S.D. (1996) Divalproex sodium in headache - literature review and clinical guidelines. Headache 36, 547-555

53. Bayer, K. et al. (2004) Gabapentin may inhibit synaptic transmission in the mouse spinal cord dorsal horn through a preferential block of P/Qtype $\mathrm{Ca}^{2+}$ channels. Neuropharmacology 46, 743-749

54. Rogawski, M.A. and Loscher, W. (2004) The neurobiology of antiepileptic drugs for the treatment of nonepileptic conditions. Nat. Med. 10, 685-692

55. Mathew, N.T. (1996) Gabapentin in migraine prophylaxis. Cephalalgia 16, 367

56. Wessely, P. et al. (1987) Preliminary results of a double-blind study with the new migraine prophylactic drug gabapentin. Cephalalgia 7, 477-478

57. Mathew, N.T. et al. (2001) Efficacy of gabapentin in migraine prophylaxis. Headache 41, 119-128

58. D'Andrea, G. et al. (2005) Migraine with aura from pathophysiology to treatment: therapeutic strategies. Neurol. Sci. 26 (Suppl. 2), S104- S107

59. Wheeler, S.D. (2001) Lamotrigine efficacy in migraine prevention. Cephalalgia 21, 374

60. Steiner, T.J. et al. (1997) Lamotrigine versus placebo in the prophylaxis of migraine with and without aura. Cephalalgia 17, 109-112

61. Lampl, C. et al. (2005) Lamotrigine reduces migraine aura and migraine attacks in patients with migraine with aura. J. Neurol. Neurosurg. Psychiatry 76, 1730-1732

62. Oshinsky, M.L. (2004) Botulinum toxin and migraine: how does it work? Practical Neurology (Suppl.), 10-13

63. Silberstein, S.D. et al. (2000) Botulinum toxin type A as a migraine preventive treatment. For the BOTOX ${ }^{\circledR}$ Migraine Clinical Research Group. Headache 40, 445-450

64. Dodick, D.W. et al. (2005) Botulinum toxin type A for the prophylaxis of chronic daily headache: subgroup analysis of patients not receiving other prophylactic medications: a randomized double-blind, placebo-controlled study. Headache 45, 315-324

65. Silberstein, S.D. (2004) Migraine. Lancet 363, 381-391

66. Silberstein, S.D. et al. (2001) Migraine: diagnosis and treatment. In Wolff's Headache and Other Head Pain (7th edn) (Silberstein, S.D. et al., eds), pp. 121-237, Oxford University Press

This is the author's final version prior to publication in Trends in Pharmacological Sciences 27(8):410-415, August 2006. The published version is available at http://dx.doi.org/10.1016/j.tips.2006.06.003, copyright $\odot 2006$ Elsevier Ltd. 